\title{
Cómo decir..
}

ANALÍA GERBAUDO Universidad Nacional del Litoral - CONICET, Argentina

ORCID 0000-0001-9969-8004

agerbaudo@fhuc.unl.edu.ar/analia.gerbaudo@conicet.gov.ar

\author{
Para Sol Viñolo, in memoriam. \\ Para los médicos y las médicas, los enfermeros y las enfermeras \\ y todo el personal de nuestro sistema público de salud.
}

folie-/folie que de-/ que de-/ comment dire-/folie que de ce-/ depuis-/folie depuis ce-/ donné-/folie donné ce que de-/vu-/folie vu ce-/ce-/ comment dire-/ ceci-/ ce ceci-/ceci-ci-/t tout ce ceci-ci-/folie donné tout ce-/vu-/ folie vu tout ce ceci-ci que de-/ que de -/comment dire-/voir-/ entrevoir-/ croire entrevoir-/vouloir croire entrevoir-/ folie que de vouloir croire entrevoir quoi-/ quoi-/comment dire-/ et où-/ que de vouloir croire entrevoir quoi où-/ où-/ comment dire-/là-/là-bas-/loin-/ loin là làbas-/à peine-/loin là là-bas à peine quoi-/ quoi-/comment dire-/vu tout ceci-/ tout ce ceci-ci-/folie que de voir quoi-/ entrevoir-/ croire entrevoir-/vouloir croire entrevoir-/loin là là-bas à peine quoi -/ folie que d'y vouloir croire entrevoir quoi-/ quoi-/comment dire-/comment dire-/

El arte ha llevado hasta donde pudo la dicción del dolor mientras, junto a la filosofía, ha vuelto reflexivamente sobre los límites de esa operación. La dificultad, tantas veces mencionada, para traducir la experiencia se estampa de forma desgarradora en estos tiempos transidos por la enfermedad y la muerte provocadas por un suceso cuyo carácter acontecimental (en el sentido derrideano de irrupción insospechada) tal vez debiéramos interrogar (la Organización Mundial de la Salud habría anticipado un fenómeno de este orden bajo el nombre de «enfermedad X» -Peyre, 2021-) así como interrogamos decisiones de gestión de la pandemia tanto a escala mundial como nacional, provincial y municipal (local, digamos), movidas por la gula económica y/o electoral más que por criterios sanitarios (Piot, 2021), para empezar, en el terreno sobre el que algo sabemos, la educación. Sin embargo, no es ese el objetivo de nuestro editorial.

Ante el temblor provocado por tanta cosa imposible de re-presentar sin demasiado resto, quienes hacemos El taco en la brea preferimos, en esta oportunidad, en principio, enviar al poema de Samuel Beckett que usamos como epígrafe. Un poema dedicado a los médicos y las médicas, las enfermeras y los enfermeros y todo el personal de nuestro sistema público de salud. 
Cualquiera que, en estos meses, haya tenido que atravesar alguna situación en un hospital (cualquiera sea: abarrotado de camas y pacientes más allá del límite de lo, hasta hace poco, imaginable) no necesita que agreguemos nada más.

El editorial también está dedicado a Sol Viñolo. Mientras se estaba evaluando un artículo suyo enviado para su publicación en esta revista, nos topamos con el texto de Gustavo Sorá que elegimos como cierre para este escrito. Nada que podamos agregar. Otra vez, sin más palabras que estas y que las de Sol cuyo artículo ponemos a circular, no solo porque contamos con la autorización de quienes fueron sus directores de investigación (Gustavo Sorá y Silvio Mattoni) sino porque, además, creemos que este gesto va en la línea de las exhumaciones a las que Gustavo invita:

\section{Solcitogloriosa}

Punzante dolor, vacío de sentidos, injusticia, garrotazo, tristeza profunda. ¿Cómo pudo ser que un ebrio destino nos dejara sin ella? Sol Viñolo. La penumbra de tanta angustia no nos dejará inmóviles, pasivos, silenciados. A horas de su muerte nos pondremos a publicar su obra naciente. Intentaremos sostener su antorcha y diseminarla. Ella permanecerá transformada, nos seguirá iluminando.

Fue un ser tan extraordinario, fuera de lo común, necesario. Se preparaba para cuestionar y transformar la cultura a golpes de rebeldía, de inteligencia, de contramarchas, de provocaciones nada gratuitas. Tanta juventud, tanta madurez, tanta sensibilidad, pasión, tesón, pulsión vital reflejaban el brillo de una familia muy singular que conocí indirectamente en la voz igualmente apasionada y contracultural de Héctor «Perro» Emaides, para quien Sol era también su hija.

Alumna brillante, lectora voraz, solcitogloriosa, como firmaba su correo, siempre estaba más allá de los programas de cursos, de las disciplinas, de lo esperable para docentes y alumnes. Abría y abría el pensamiento, desparramaba interrogantes originales, bien orientados a develar temas, signos inadvertidos para cualquier otre. Cursaba la licenciatura en Antropología de la UNC y militaba en el Partido Obrero. Tal ciencia le aportó instrumentos de alternización que le permitieron mirar con sagacidad la centralidad que en su Partido tenía la cultura escrita: bibliotecas, periódicos, formación, educación popular. Para sopesar esa función intelectual, central en el devenir de las izquierdas, le propuse comparar el PO con la Unión Cívica Radical, partido tradicional y hace tiempo desfigurado al punto de comprobar Sol con su etnografía que de la pluma en el escudo de la UCR sólo queda un «yermo páramo». Las fronteras a menudo tan rígidas del PO, de la antropología le eran insoportables. Hizo suya una actitud heterodoxa, movediza y bien pertrechada para atravesar fronteras. Inconforme con dogmas, con la violencia simbólica de instituciones e ideas normadas, antes de graduarse dejó el Partido e hizo un movimiento esperable para alguien como ella: atravesar aduanas culturales que duramente cuestionaba para moverlas, sacudirlas, erradicarlas. Se inscribió en letras, carrera donde se aproximó a Silvio Mattoni, brillante intelectual. No conforme, ladeó hacia la filosofía. Devoraba paradigmas, los saboreaba en busca de preguntas propias. En ningún momento me opuse a ese desafío. Sólo le insistía en que no dejara de confiar en la etnografía como arte para observar a fondo, más allá de lo evidente. Derrida la fascinaba. El tema de la escritura permaneció en el eje de su cosmología. Leía y escribía con facilidad, con personalidad, con acento. Era esperable que ya en el doctorado tomara a la poesía como tema. ¿Dónde está la poesía en Córdoba? ¿Qué espacios habita? ¿Quiénes la impulsan? Pocas manifestaciones culturales abarcan un ambiente tan amplio, tan diverso entre 
los márgenes de lo marginal y la coraza de los cánones y panteones resguardados en/por la universidad. Comenzó a componer su propio repertorio de escritores, editoriales, eventos, librerías, bibliotecas, huellas del asunto en donde no se suponía que existiera. Y la actitud de etnógrafa la deparó con lo que vislumbró como la dimensión más pulsante para su persona: la poesía trans. Lugar, tema, proyecto que urdió con su amor por Fernanda, realizadora visual a quien Sol animó para romper los moldes de la monografía e imaginar de a dos un experimento que sólo podría ser retratado por múltiples herramientas de registro y de comunicación. A pesar de la pandemia se las ingenió para no abandonar «el campo». La poesía se hizo cuerpo en Sol. Un día sorprendió a Mariana (mi compañera, antropóloga, poeta e inclasificable como Sol, no por nada tan cómplice de ella) con el envío de un proyecto de investigación científica escrito en verso!

Libre y cuestionadora, no le esquivaba a los compromisos institucionales para hacerse de una profesión intelectual, para conseguir medios materiales como inexorables requisitos para que su labor fuera reconocible y se proyectara como trabajo. El oficio ya había sido incorporado. La profesión abría caminos. Ganaba becas. A veces también era mal juzgada o incomprendida. Siempre comprometida con alguna causa política y dispuesta a la inmersión en el arte, no perdía su norte y alternaba tiempos de alejamiento del mundo institucional y tiempos de rigurosa dedicación al trabajo de cátedra, a las exigencias de informes, de exámenes. Un tema la angustiaba: la necesidad de darse a conocer, de publicar. Sus escritos no son convencionales. Como todo escritor, sufrió más de un rechazo. Volvió a desconfiar, a ocultarse. Entre la necesidad de acumular recursos para avanzar en una carrera y el deseo de mostrar su pensamiento, hace pocas semanas volvió sobre ese límite y deseo como solía hacerlo: con capacidad, rapidez, convencimiento. La tesina «Literatura y política desde el lector. Militancia y cultura escrita en Córdoba» debía ser apenas repasada para que varias editoriales se disputaran su publicación. Al menos, le insistía, algunos capítulos o partes merecían el formato de artículos: nada de lo que escribió Sol tenía correlato en la masa de la producción académica argentina. Pero ella iba hacia adelante y el trabajo para esa transformación ya estaba ocupado por otros asuntos de mayor interés. Sólo recientemente volvió a la tesina y se dio cuenta de lo bien que estaba, de que no era serio dejar el manuscrito como un signo apenas habilitante del título de Licenciada, obtenido a finales del 2015. Aprovechamos el retorno, el necesario envión. Preparó un segmento de la tesina que envió para referato a la prestigiosa revista Políticas de la Memoria (Cedinci). Al día siguiente envió otra parte a la Revista del Museo de Antropología. Estaba feliz y preparaba nuevos envíos. Serán dos huellas publicadas de sus aportes. Las primeras veinte páginas de su tesis doctoral sobre la poesía trans son notables. Pronto también podremos editarlas.

Revolucionaria, poeta, subversiva. Sol no nos perdonaría que nos quedemos impávidos, vacíos, tristes. Su presencia nos llama a la reflexión profunda, a luchar contra las injusticias que siembra el capitalismo, a cuestionar dogmas e ideas convencionales. Muches visitarán su biblioteca, su archivo, y un ineludible ejercicio de memoria asegurará la extensión de su proyecto. Sol Viñolo. Será nombrada una y otra vez como un ejemplo nada fugaz para quienes queremos cuestionar la realidad con descubrimientos insospechados. Te querremos siempre. Gracias Sol por invitarnos a acompañarte en algún tramo de tu gloriosa vida. 


\section{Notas}

1 locura-/locura de-/de-/cómo decir-/locura de este-/desde-/locura desde este-/ dado-/locura dado lo que de-/visto-/ locura visto este-/ este-/ cómo decir-/ esto-/ este esto-/ esto aquí-/ todo este esto aquí-/locura dado todo lo-/visto-/ locura visto todo este esto aquí de-/ de-/ cómo decir-/ver-/ entrever-/ creer entrever-/ querer creer entrever-/locura de querer creer entrever qué-/ qué-/ cómo decir-/y dónde-/ de querer creer entrever qué dónde-/ dónde-/ cómo decir-/ allí-/ allá-/ lejos-/ lejos allí allá-/ apenas-/lejos allí allá apenas qué-/ qué-/ cómo decir-/visto todo esto-/ todo este esto aquí-/locura de ver qué-/ entrever-/ creer entrever-/ querer creer entrever-/lejos allí allá apenas qué-/locura de allí querer creer entrever qué-/ qué-/ cómo decir-/ cómo decir-/ (Traducción de Laura Cerrato)

\section{Referencias}

Peyre, M. (2021). Entrevista. La méthode scientifique. France culture. https://www.franceculture.fr/emissions/ la-methode-scientifique/pandemies-la-menace-fantome

Piot, P. (2021). Lâge des pandémies. Université populaire. Musée du quai Branly. https://www.franceculture. fr/conferences/musee-du-quai-branly-jacques-chirac/lage-des-pandemies 